\title{
Effectiveness of Pre-operative Rectal Misoprostol in Reducing Blood Loss during Cesarean Section for Placenta Previa and Manual Removal of Retained Placenta: A Parallel Placebo- Controlled Study
}

\author{
Ubong Akpan ${ }^{1 *}$, Udeme Asibong ${ }^{2}$, Kazeem Arogundade $^{3}$, Chinyere Akpanika ${ }^{1}$, Mabel Ekott $^{1}$, Saturday Etuk $^{1}$ \\ ${ }^{1}$ Department of Obstetrics and Gynaecology, University of Calabar Teaching Hospital, Calabar, Nigeria; ${ }^{2}$ Department of Family \\ Medicine, University of Calabar Teaching Hospital, Calabar, Nigeria; ${ }^{3}$ Bruyere Research Institute, Ottawa, Canada
}

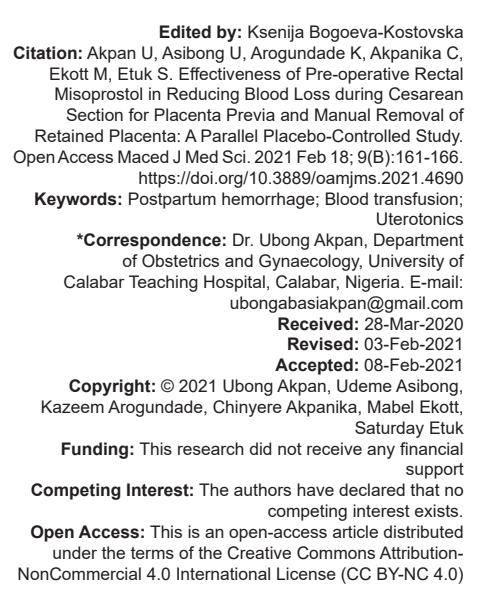

\begin{abstract}
BACKGROUND: Primary postpartum hemorrhage (PPH) contributes significantly to the high maternal mortality ratio, especially in the low resource nations. Placenta previa and retained placenta are major causes of postpartum hemorrhage. Uterotonics like misoprostol are medication used to improve uterine contractility with the purpose of reducing uterine bleeding after delivery of baby. Most studies on misoprostol for the prevention of obstetric hemorrhage have been focusing on its postpartum use.

AIM: The aim of this study was to assess the effectiveness of pre-operative misoprostol in reducing blood loss during cesarean section for placental previa and manual removal of retained placenta.

METHODS: This was a placebo-controlled study involving 154 women who were randomly assigned to the treatment and control groups. The study group received $400 \mathrm{ug}$ of misoprostol rectally just before the commencement of the procedure. Estimation of blood loss was done in a standardized way. Data were analyzed using SPSS version 23 The level of significance was set at $p<0.05$.

RESULTS: The average age of the participants was 31.64 years. The overall incidence of PPH was comparable in both groups (0.070), however, misoprostol group experienced lower incidence of severe PPH compared to the placebo $(p=0.013)$. Other maternal and perinatal outcomes were comparable.

CONCLUSION: Excessive intraoperative and immediate post-operative bleeding can be prevented with preoperative misoprostol. It should be made available for high-risk obstetrics procedures.
\end{abstract}

\section{Introduction}

Conventionally, uterotonics such as oxytocin, ergometrine, and misoprostol are routinely administered after the delivery of the fetus and may not reduce the intraoperative blood loss (part of PPH) in the women undergoing obstetric surgical procedures [1]. This intraoperative bleeding can significantly lead to maternal morbidity and mortality [2]. Besides, the time lag between uterotonic administration and onset of action is critical for the survival of the patient in situation of massive bleeding immediately following childbirth [2].

Placental abnormalities are a major contributor to obstetric hemorrhage [3], [4], [5]. The common abnormalities encountered in pregnancy include placental abruption, placental previa, morbidity adherent placentae (accrete, increta, and percreta), and retained placenta. These abnormalities, for example, accounted for $36 \%$ of pregnancy-related deaths due to hemorrhage in one series [5], [6].
Operation for these placenta abnormalities is known to be associated with significant intraoperative bleeding which may be life threatening [7]. Achieving uterine contractility during this critical period using a highly potent uterotonic like misoprostol may be lifesaving. Pathological adherence of the placenta (accreta) to the uterine surface may complicate placental previa and retained placenta. It is a known cause of massive obstetric hemorrhage and a common indication for peripartum hysterectomy [1], [7]. Retained placenta is a complication of third stage of labor. Most often, patients with retained placenta are taken to theater for manual removal of the placenta. It is commonly associated with obstetric hemorrhage [1]

The advent of misoprostol has revolutionized obstetric practice. It is a synthetic prostaglandin E1 analog. It is available in tablet forms and has numerous advantages - stability in room temperature, long shelf-life, low cost, and multiple routes of administration (orally, sublingually, vaginally, and rectally) [4]. Following administration, misoprostol is 
rapidly absorbed [4]. Misoprostol is commonly used for cervical ripening and induction of labor $(25-50 \mu \mathrm{g}$ $6 \mathrm{~h})$ and for prevention and treatment of postpartum hemorrhage (400-1000 $\mu \mathrm{g})$ [3], [4]. The common side effects include diarrhea, abdominal pain, and hyperthermia when used at higher doses [4]. These side effects are less likely when administered locally (vaginally or rectally).

Most studies on misoprostol for the prevention of obstetric hemorrhage have been focusing on its use postpartum. In many cases when the woman must have lost significant amount of blood intrapartum. As placenta abnormalities are most often the predisposing factors for hemorrhage intrapartum, it may be imperative to assess the possible impact of this commonly used uterotonic in reducing maternal morbidity and mortality.

\section{Subjects and Methods}

The study was conducted in three health facilities, University of Calabar Teaching Hospital (UCTH), Army Medical Center, and Calabar Women and Children Hospital all in Calabar, South Nigeria, from January 1, 2015, to December 31, 2017. Multiple centers were involved due to the low incidence of these conditions. These facilities were selected due to their specialized role in the management of highrisk pregnancies. Before the commencement of the research, a pilot study was carried out with 10 patients with placenta previa (mostly of Jehovah witness who declined blood transfusion) in the General Hospital Calabar to test run the protocol for flaws.

One hundred and fifty-four women who met the criteria were included in the study. Seventy-seven of them received $400 \mu \mathrm{g}$ of rectal misoprostol (study group) while another 77 received placebo (control group). Computer-generated random number was used to assign participants. All the participants received at least 10 iu of oxytocin at the delivery of the baby. The diagnosis of placenta previa was made from ultrasound scan in the third trimester. The misoprostol was inserted after induction of anesthesia when the surgeon and the assistant had gowned and gloved.

Blood loss estimation involved direct measurement and extrapolation from the suction cylinders or other receptacles, abdominal mops, and swabs. The linens were weighted before (dry weight) and after the procedure. A separate suction device was used for the liquor. For the mops and gauze, the standard estimation used in UCTH is $150 \mathrm{ml}$ for one fully soaked abdominal mop and $25 \mathrm{ml}$ for one fully soaked cotton wool wrap gauze (Figures 1 and 2). The primary and secondary outcomes of interest were documented.

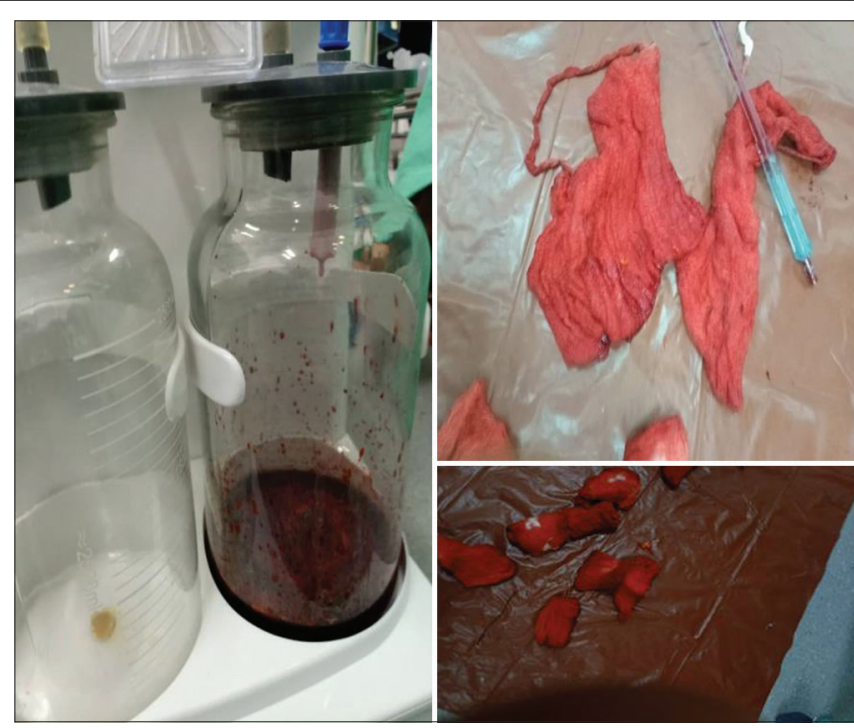

Figure 1: Diagram on methods of the estimation of blood

\section{Primary outcome measure}

Volume of blood loss (mean blood loss).

\section{Secondary outcome measures}

1. Maternal mortality following primary postpartum hemorrhage.

2. Additional surgeries such as laparotomy, brace suturing, and hysterectomy.

3. Need for blood transfusion.

4. Postpartum anemia, febrile disorders, and duration of hospital stay.

5. Perinatal outcomes like low APGAR score at 5 min and admission to neonatal intensive care unit.

\section{Inclusion criteria}

The following criteria were included in the study:

- $\quad$ Term pregnancy (37 completed weeks of gestation).

Informed consent.

Placenta previa diagnosed with ultrasound scan and clinically diagnosed retained placenta.

\section{Exclusion criteria}

The following criteria were excluded from the study:

- $\quad$ Preterm delivery.

- $\quad$ Multiple pregnancies.

- $\quad$ Three or more previous cesarean section.

- $\quad$ Contraindications or allergy to misoprostol like asthma.

Antepartum hemorrhage.

Those with retained placenta with more than $24 \mathrm{~h}$ from time of delivery. 


\section{Ethical issues}

Before commencement of the study, approval was obtained from the hospital research ethics committee. Participation was voluntary. Informed consent was obtained from each participant. Those who had PPH were given standard treatment.

\section{Results}

Seventy-four cases in the study and 75 in the control were included in the analysis. Five of them were not included in the analysis because the intraoperative findings were different from the pre-operative diagnosis. The mean ages in years of the women were 37.74 and 31.54 in the study and controlled groups, respectively. A vast majority of the women in both groups were of low parity ( 3 and below). Table 1 shows that there was no significant difference in age, parity, and booking status in both groups. Regional anesthesia (spinal and epidural) was utilized in $105(70.5 \%)$ while general anesthesia was used in $44(29.5 \%)$ of the cases.

The amount of blood loss was classified into normal, postpartum hemorrhage $(500 \mathrm{ml}$ or more for MROP and $1000 \mathrm{ml}$ or more for cesarean section), and severe postpartum hemorrhage $(1500 \mathrm{ml}$ or more). The overall incidences of postpartum hemorrhage in both arms were comparable $(p=0.07)$. However, women in the control group were more likely to experience severe bleeding (19 [25.3\%] vs. 8 [10.8\%]). The mean blood loss was significantly lower in the misoprostol group compared to the control $(780 \pm 476.9 \mathrm{ml}$ vs. $1060.6 \pm 829.9 \mathrm{ml}, \mathrm{p}=0.013)$. Similarly, the mean units of blood transfusion were significantly lower in the misoprostol arm compared to the placebo $(p=0.003)$ (Table 2).

Table 3 shows the relationship between the methods of anesthesia and uterine bleeding. There was

Misoprostol group $\mathrm{N}=74$ $\mathrm{C} / \mathrm{S} \mathrm{N}=39$ ESTIMATED BLOOD LOSS SECONDARY OUTCOMES

Figure 2: Flow diagram summarizing the research protocols

Table 1: Sociodemographic, bleeding, booking, and anesthetic characteristics

\begin{tabular}{|c|c|c|c|c|c|}
\hline & Case $n=74$ & Control $n=75$ & Total $n=149$ & Chi-square test & $p$-value \\
\hline \multicolumn{6}{|l|}{ Age group/years } \\
\hline $20-29$ & $23(31.1)$ & $24(32.0)$ & 47 (31.5) & 0.233 & 1.000 \\
\hline $30-39$ & $48(64.9)$ & $47(62.7)$ & $95(63.8)$ & & \\
\hline $40-49$ & $3(4.1)$ & $4(5.3)$ & $7(4.7)$ & & \\
\hline Mean age/SD & $31.7 / 4.2$ & $31.5 / 4.4$ & $31.6 / 4.3$ & t-test, 0.200 & 0.842 \\
\hline \multicolumn{6}{|l|}{ Parity group } \\
\hline Low (1-3) & 60 (81.1) & 74 (98.7) & 134 (89.9) & 12.723 & $0.000^{*}$ \\
\hline High $(>3)$ & 14 (18.9) & $1(1.3)$ & $15(10.1)$ & & \\
\hline \multicolumn{6}{|l|}{ Booking status } \\
\hline Booked & 68 (91.9) & 67 (89.3) & $135(90.6)$ & 0.286 & 0.593 \\
\hline Unbooked & $6(8.1)$ & $8(10.7)$ & $14(9.4)$ & & \\
\hline \multicolumn{6}{|l|}{ Anesthetic } \\
\hline General & $19(25.7)$ & $25(33.3)$ & $44(29.5)$ & 1.050 & 0.306 \\
\hline Regional & 55 (74.3) & $50(66.7)$ & $105(70.5)$ & & \\
\hline
\end{tabular}

Table 2: Effect of misoprostol on total blood loss compared to the control group

\begin{tabular}{|c|c|c|c|c|c|}
\hline & Case $n=74$ & Control $n=75$ & Total $\mathrm{n}=149$ & Chi-square test & $\mathrm{p}$-value \\
\hline \multicolumn{6}{|l|}{ Blood loss } \\
\hline Normal & $48(64.9)$ & $40(53.3)$ & $88(59.1)$ & 5.320 & 0.070 \\
\hline $\mathrm{PPH}$ & $18(24.3)$ & $16(21.3)$ & $34(22.8)$ & & \\
\hline Severe PPH $(\geq 1500 \mathrm{ml})$ & $8(10.8)$ & $19(25.3)$ & $27(18.1)$ & & $0.001^{*}$ \\
\hline Mean blood loss $\pm S D$ & $780.4 \pm 476.9$ & $1060.6 \pm 829.9$ & $921.4 \pm 690.2$ & t-test, 2.531 & $0.013^{*}$ \\
\hline Mean number of blood transfusion $\pm \mathrm{SD}$ & $0.3 \pm 0.7$ & $0.8 \pm 1.2$ & $0.5 \pm 1.0$ & t-test, 3.065 & $0.003^{*}$ \\
\hline Mean duration of hospital stay \pm SD & $1.4 \pm 0.5$ & $1.2 \pm 0.4$ & $3.3 \pm 1.1$ & 1.856 & 0.065 \\
\hline
\end{tabular}


no significant influence of any method used (regional or general) on the incidence of PPH ( $p=0.068)$.

Table 3: Association between mode of anesthesia and blood loss

\begin{tabular}{llllll}
\hline & \multicolumn{2}{l}{ Mode of anesthesia } & & & \\
\cline { 2 - 6 } & $\begin{array}{l}\text { General 44 } \\
(100.0)\end{array}$ & $\begin{array}{l}\text { Regional 105 } \\
(100.0)\end{array}$ & $\begin{array}{l}\text { Total 149 } \\
(100.0)\end{array}$ & $\begin{array}{l}\text { Chi-square } \\
\text { test }\end{array}$ & p-value \\
\hline Blood loss & $20(45.5)$ & $68(64.8)$ & $88(59.1)$ & 5.386 & 0.068 \\
$\quad$ Normal & $12(27.3)$ & $22(21.0)$ & $34(22.8)$ & & \\
PPH & $12(27.3)$ & $15(14.3)$ & $27(18.1)$ & & \\
$\quad$ Severe PPH & 12 &
\end{tabular}

The effect of misoprostol on the secondary outcomes of interest was assessed. Two women in the study group had peripartum hysterectomy due to uncontrolled bleeding while three cases of hysterectomy were recorded among the controls due to severe PPH. Other additional procedures included two "Brace suturing" of the placental bed in the treatment arm and one in the controlled while one woman in the placebo arm had bilateral uterine artery ligation (Figure 3). There were no significant differences in other maternal and perinatal complications between the study and the control groups, as shown in Table 4. Similarly, fetal weight did not significantly correlate with the volume of blood loss.

In considering birth weight as a major cofounding factor for blood loss during delivery, the study shows a weak positive correlation between infant weight and postpartum hemorrhage (Table 5).

The place of delivery especially for retained placenta (within or outside hospital) did not influence postpartum bleeding and other peripartum outcomes (Table 6).

\section{Discussion}

Placenta previa and morbidly adherent placenta as well as retained placenta are major risk factors for postpartum hemorrhage. This is shown in the study where a high incidence of $22.8 \% \mathrm{PPH}$ was documented among all the participants with these conditions compared to incidence of $5-10 \%$ reported for cesarean section for other indications and 1-5\% following vaginal delivery [1], [4], [8]. Hence, this study unlike other researches was conceived to specifically target these major risk factors that often threaten maternal lives during childbirth. The study revealed that misoprostol administration preoperatively is highly effective in preventing severe $\mathrm{PPH}$ and consequently the risk of blood transfusion during cesarean section and manual removal of retained placenta. The previous studies have also proved that misoprostol was more effective than placebo in the prevention and treatment of PPH [3], [4]. In this study, women in the control group received more units of blood transfusion compared to the study arm $(p=0.003)$. A recent population-based study has shown that massive blood transfusion occurs in 5.3 per 100,000 deliveries and abnormal placentation is the most common risk factor [3].

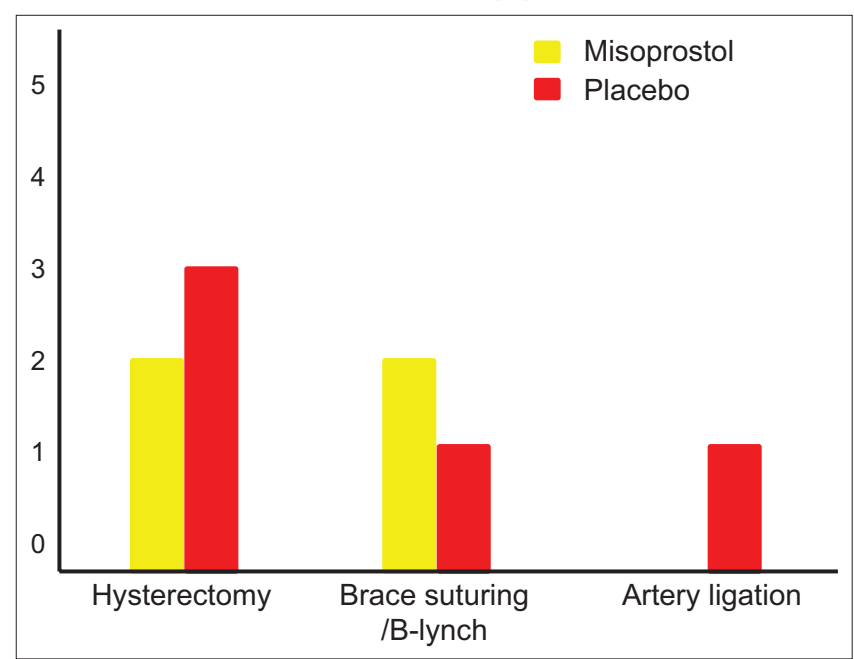

Figure 3: Additional procedure

The timing and the routes of drug administration are vital for optimal benefit. Misoprostol can be administered through oral, sublingual, vaginal, or rectal route. Sublingual and oral routes are said to have rapid rates of absorption and may lead to uterine rupture if the baby is not delivered immediately [4]. The mean time of maximum plasma concentration for sublingual route is $7.8 \pm 3.0$ min while the mean time for rectal and vaginal

Table 4: Effect of misoprostol on pregnancy outcome among cases and control $(n=149)$

\begin{tabular}{|c|c|c|c|c|c|}
\hline Variable & Case $\mathrm{n}=74$ & Control $n=75$ & Total $\mathrm{n}=149$ & Chi-square test & $\mathrm{p}$-value \\
\hline \multicolumn{6}{|l|}{ Birth weight/kg } \\
\hline Low & $9(12.2)$ & $13(17.3)$ & $22(14.8)$ & \multirow[t]{3}{*}{ FET,1.139 } & \multirow[t]{3}{*}{0.570} \\
\hline Normal & $59(79.7)$ & $58(77.3)$ & $117(78.5)$ & & \\
\hline Macrosomia & $6(8.1)$ & $4(5.3)$ & $10(6.7)$ & & \\
\hline \multicolumn{6}{|l|}{ Fetal complications } \\
\hline Alive/well & $62(83.8)$ & $66(88.0)$ & $128(85.9)$ & \multirow[t]{3}{*}{ FET, 0.773} & \multirow[t]{3}{*}{0.826} \\
\hline Perinatal death & $2(2.7)$ & $2(2.7)$ & $4(2.7)$ & & \\
\hline Neonatal intensive care admission & $10(13.5)$ & $7(9.3)$ & $17(11.4)$ & & \\
\hline \multicolumn{6}{|l|}{ Blood loss } \\
\hline Normal & $48(64.9)$ & $40(53.3)$ & $88(59.1)$ & \multirow[t]{2}{*}{5.320} & \multirow[t]{2}{*}{0.070} \\
\hline Severe PPH & $8(10.8)$ & $19(25.3)$ & $27(18.1)$ & & \\
\hline \multicolumn{6}{|l|}{ Maternal complications } \\
\hline None & $68(91.9)$ & $66(88.0)$ & $134(89.9)$ & \multirow{5}{*}{ FET,4.322 } & \multirow{5}{*}{0.362} \\
\hline Pyrexia & $4(5.4)$ & $7(9.3)$ & $11(7.4)$ & & \\
\hline Wound infection & $1(1.4)$ & $0(0.0)$ & $1(0.7)$ & & \\
\hline Hysterectomy & $2(2.7)$ & $3(4.0)$ & $5(3.4)$ & & \\
\hline Maternal death & $0(0.0)$ & $0(0.0)$ & $0(0.0)$ & & \\
\hline \multicolumn{6}{|l|}{ Duration of hospital stay } \\
\hline $1-3$ days & $47(63.5)$ & $58(77.3)$ & $105(70.5)$ & \multirow[t]{2}{*}{3.419} & \multirow{2}{*}{0.064} \\
\hline$>3$ days & $27(36.5)$ & $17(22.7)$ & $44(29.5)$ & & \\
\hline
\end{tabular}


Table 5: Association between birth weight and blood loss

\begin{tabular}{llllll}
\hline & \multicolumn{3}{l}{ Birth weight } & & \\
\cline { 2 - 5 } & LBW & Normal \\
$\mathrm{n}=22$ & $\mathrm{n}=117$ & $\begin{array}{l}\text { Macrosomia } \\
\mathrm{n}=10\end{array}$ & Fisher's exact test & $\mathrm{p}$-value \\
\hline Blood loss & & & & & \\
$\quad$ Normal & $11(50.0)$ & $71(60.7)$ & $6(60.0)$ & 2.150 & 0.678 \\
PPH & $7(31.8)$ & $24(20.5)$ & $3(30.0)$ & & \\
Severe PPH & $4(18.2)$ & $22(18.8)$ & $1(10.0)$ & & \\
\hline
\end{tabular}

roots is $20.9 \pm 5.3 \mathrm{~min}$ [4]. The mean time interval from skin incision to the delivery of the baby during cesarean section is $10-15$ min depending on the type of incision and the presence of adhesions in the surgical field [9]. For this reason, rectal route was preferred in this study. There was no case of uterine rupture among the cases. The common side effects reported were mostly due to gastrointestinal effects. There was no fatal drug reaction. This is in keeping with previous finding [7].

Table 6: Place of delivery and blood loss, hospital stay maternal and perinatal outcome

\begin{tabular}{|c|c|c|c|c|c|}
\hline & \multicolumn{3}{|c|}{ Place of delivery } & & \\
\hline & $\begin{array}{l}\text { Home } \\
\mathrm{n}=6\end{array}$ & $\begin{array}{l}\text { Hospital } \\
n=143\end{array}$ & $\begin{array}{l}\text { Total } \\
n=149\end{array}$ & & \\
\hline \multicolumn{6}{|l|}{ Blood loss } \\
\hline Normal & $3(50.0)$ & $85(59.4)$ & $88(59.1)$ & FET,4.046 & 0.060 \\
\hline PPH & $0(0.0)$ & $34(23.8)$ & $34(22.8)$ & & \\
\hline Severe PPH & $3(50.0)$ & $24(16.8)$ & $27(18.1)$ & & \\
\hline \multicolumn{6}{|c|}{ Duration of hospital stay } \\
\hline $1-3$ days & $5(83.3)$ & $100(69.9)$ & $105(70.5)$ & FET,0.497 & 0.671 \\
\hline$>3$ days & $1(16.7)$ & $43(30.1)$ & 44 (29.5) & & \\
\hline \multicolumn{6}{|l|}{ Fetal outcome } \\
\hline Alive/well & $6(100.0)$ & $122(85.3)$ & $128(85.9)$ & FET,0.620 & 1.000 \\
\hline SCBU & $0(0.0)$ & $17(11.9)$ & $17(11.4)$ & & \\
\hline Death & $0(0.0)$ & $4(2.8)$ & $4(2.7)$ & & \\
\hline \multicolumn{6}{|c|}{ Maternal complication } \\
\hline None & $5(83.3)$ & $129(90.2)$ & $134(89.9)$ & FET,5.313 & 0.470 \\
\hline Pyrexia & $1(16.7)$ & $10(7.0)$ & $11(7.4)$ & & \\
\hline Hysterectomy & $0(0.0)$ & $1(0.7)$ & $1(0.7)$ & & \\
\hline Wound infection & $0(0.0)$ & $1(0.7)$ & $1(0.7)$ & & \\
\hline
\end{tabular}

The choice of anesthesia was influenced by the patient morbid state and was at the discretion of the anesthetists. General anesthesia was commonly utilized for manual removal of retained placenta. The halothane component of the anesthesia is believed to allow for easy entry into the uterine cavity and prevent vasovagal shock from cervical dilatation. However, subgroup analysis shows that there was no significant correlation between the type of anesthesia and quantity of blood loss. This finding contradicts previous reports [7], [10]. Although the halothane anesthesia is commonly linked with increased blood loss due to uterine relaxation effect, the pre-operative misoprostol must have countered this unwanted side effect [7]. This was also demonstrated in a previous study which proved that sublingual pre-operative misoprostol effectively improved uterine tone during isoflurane anesthesia for cesarean section [10].

The need for additional treatment such as Brace/B-Lynch suturing, uterine, and iliac artery ligation and hysterectomy was comparable in both groups. This is in contrast with a previous study which revealed that women who received pre-operative misoprostol significantly had lower risk of additional operative intervention [11]. This could be due to other cofounding factors such as previous multiple uterine surgery and the surgical techniques. In this study, patient selection, randomization, strict diagnostic criteria, and matching of controls for parity prevented bias and sample contamination. Women with more than 2 previous cesarean section or previous myomectomies or metroplastic surgeries were excluded from the study.

Furthermore, there was no significant relationship between birth weight and blood loss during cesarean section contrary to previous reports [7], [9]. Apart from the increased need for blood transfusion in the controls compared to the study group ( $p=0.003)$, other maternal and perinatal outcomes were similar. These were in keeping with two previous randomized studies [11], [12].

\section{Conclusion}

Misoprostol should be considered as one of the most important drugs in preventing massive hemorrhage and blood transfusion when planning for elective cesarean section for placenta previa. It is also effective in reduction of bleeding during manual removal of retained placenta. However, its secondary effects on other maternal and perinatal outcomes may warrant more large-scale studies.

\section{Acknowledgment}

We wish to acknowledge the management and staff, particularly the nursing staff of the three health facilities, where the study was conducted for their immense contribution to the success of the study.

\section{Limitations}

The main challenge in the studies involving obstetric hemorrhage has always been the methods in the calculation of blood loss [13], [14], [15], [16], [17], [18], [19], [20]. In this research, as much as possible, this was reduced to the minimal level by utilizing standard methods of the assessment of blood loss. The main fact was that the same methods of estimation were utilized for the two arms.

\section{References}

1. Mehasseb K, Konje JC. Placental abnormalities. In: Lynch C Keith LG, Lalonde AB, Karoshi M, editors. A Textbook of Postpartum Haemorrhage. Duncow, UK: Sapiens Publishing; 2006. p. 80-95. 
2. Knight M, Callaghan WM, Berg C, Alexander S, BouvierColle $\mathrm{MH}$, Ford JB, et al. Trends in postpartum haemorrhage in high resource countries: A review and recommendations from the international postpartum haemorrhage collaborative group. BMC Pregnancy Childbirth 2009;9:55. https://doi. org/10.1186/1471-2393-9-55

3. Thurn L, Wikman A, Westgren M, Lindqvist PG. Massive blood transfusion in relation to delivery: Incidence, trends and risk factors: A population-based cohort study. BJOG. 2019;126(13):1577-86. https://doi.org/10.1097/01 aoa.0000693684.70869.3a

PMid:31483935

4. Bellad MB, Goudar S. Misoprostol: Theory and practice. In: Lynch CB, Keita LG, editor. A Textbook of Postpartum Haemorrhage. Duncow, UK: Sapiens Publishing; 2006. p. 114-26.

5. Chickakli LO, Atrash HK, Mackay AP, Musani AS, Berg CJ. Pregnancy-related mortality in the United states due to haemorrhage: 1979-1992. Obstet Gynecol. 1999;94(Pt 1):7215. https://doi.org/10.1097/00006250-199911000-00015 PMid: 10546717

6. Chong YS, Su LL, Arulkumaran S. Misoprostol: A quarter century of use, abuse, and creative misuse. Obstet Gynecol Survey. 2004;59(2):128-40. https://doi.org/10.1097/01. ogx.0000109168.83489.66 PMid:14752301

7. Elsedeek MS. Impact of preoperative rectal misoprostol on blood loss during the after elective caesarean delivery. Int $J$ Gynaecol Obst. 2012;118(2):149-52. https://doi.org/10.1016/j. ijgo.2012.03.038 PMid:22698700

8. Afolabi MA, Ezeoke GG, Saidu R, ljaiya MA, Adeniran AS Comparing perioperative vaginal misoprostol with intraoperative pericervical hemostatic tourniquet in reduction blood loss during abdominal myomectomy: A randomized controlled trial. J Turk Gercynecul Assoc. 2019;20(1):23-30. https://doi.org/10.4274/ jtgga.galenos.2018.2018.0049

PMid:30499282

9. Bajwa SK, Bajwa SJ, Kaur H, Goraya PS, Singh A, Kaurlshar H. Management of third stage of labour with misoprostol: A comparison of three routes of administration. Perspect Clin Res. 2012;3(2):102-8. https://doi.org/10.4103/2229-3485.100666 PMid:23125961

10. Ngwenya S. Postpartum haemorrhage: Incidence, risk factors, and outcomes in a low resource setting. Int J Women Health. 2018;8:647-50. https://doi.org/10.2147/ijwh.s119232 PMid:27843354

11. Maged AM, Farzi T, Shalahy MA, Samy A, Rabee MA, Ali AS, et al. A randomized controlled trial of the safety and efficacy of preoperative rectal misoprostol for prevention of intraoperative and postoperative blood loss at elective caesarean delivery. Int J Gynaecol Obstet. 2019;147(1):102-7. https://doi.org/10.1002/ ijgo.12922

\section{PMid:31304593}

12. Hofmeyr GJ, Giilmezoglu AM, Novikova N, Linder V, Ferreira S, Piaggio G. Misoprostol to prevent and treat postpartum haemorrhage: A systemic review and meta-analysis of maternal deaths and dose-related effects. Bull World Health Organ. 2009;87(9):666-77. https://doi.org/10.2471/blt.08.055715 PMid:19784446

13. Carroli G, Gusta C, Abalos E, Gulmezogolu AM. Epiemiology of postpartum haemorrhage: A systematic review. Best Pract Res Clin Obstet Gynaecol. 2008;22(6):999-1012. https://doi. org/10.1016/j.bpobgyn.2008.08.004 PMid:18819848

14. Hua J, Chen G, Xing F, Scott M. Effect of misoprostol versus oxytocin during caesarean section: A systemic review and meta-analysis. BJOG. 2013;120(5):531-40. https://doi. org/10.1111/1471-0528.12134 PMid:23331998

15. Eunkin J, Lee JH, Jukim E, Min MW, Ban JS, Lee SG. The effect of type of anaesthesia on intra and post-operative blood loss at elective caesarean section. Korean J Anaesthesiol. 2012;62(2):125-9. PMid:22379566

16. Afolabi BB, Lesi FA, Mera NA. Regional versus general anasethesia for caesarean section. Cochrane Database Syst Rev. 2006;10:CD004350. https://doi.org/10.1002/14651858. cd004350.pub2

PMid:23076903

17. Tahan MR, Rashid A. Effects of pre-operative sublingual on uterine tone during isoflurane anasethesia for caesarean section. Rev Bras Anaestesiol. 2012;62(5):625-6.

PMid:22999396

18. Rossoum JN, Hall D, Harvey J. Time between skin incision and delivery during caesarean section. Int J Gynecol Obstet. 2013;121(1):82-5. PMid:23340272

19. Ragab A, Barakat R, Alsammani MA. A randomized clinical trial of pre-operative versus post-operative misoprostol in elective caesarean delivery. Int J Gynecol Obstet. 2016;132(1):82-4. https://doi.org/10.1016/j.ijgo.2015.06.057 PMid:26522140

20. Asibong U, Akpan UB, Ayi E. Active management of third stage of labour: Knowledge and practice among non-physician obstetric care-givers in primary health Care Setting in Calabar Municipality, South-South Nigeria. Res Obstet Gynecol. 20018;6(1):9-15. 